\title{
Application of a semi-automatic method for optimal ramp design
}

\author{
CA Cerón Andrés Bello National University, Chile \\ P Nancel-Penard AMTC, University of Chile, Chile \\ N Morales AMTC, University of Chile, Chile
}

\begin{abstract}
The problem of strategic open pit planning involves several stages, including (1) pushback optimization, (2) open-pit design, and (3) production planning. To address stages (1) and (3), mine planners rely on different software optimization to assist them in making the best choices within the boundaries of these tools. However, for (2) this task, which consists of designing the actual ramps and slopes of the pit, is mostly manual, hence time-consuming and highly dependent on the expertise of the planner. In this work, we use a previously introduced mathematical model to assist the design of ramps in open pit mines. The model starts with a pre-defined pushback (in terms of blocks) and generates a "corrected" envelop which is as close as possible to the original one, but with space for designing a phase that includes ramps. To carry out this work, an analysis of the application of the assisted design of ramps in four mining operation is carried out and compared with the use of the current design methodology. This way, the differences between the operational models of both methodologies and the final pit for every case study are sought through economic benefit and the number of reserves. When applying both design methodologies, it has been obtained as a result that in all cases of studies, with the method of assisted ramp design, a slight improvement in the economic benefit is achieved.
\end{abstract}

\section{Introduction}

The design of an operational pit is a process where the planner must generate the phases, ensuring access to all active banks using a ramp. Ramps are one of the most critical aspects, and their presence must be included in the mine planning process, as they have a significant effect on reserves across the global angle (Hustrulid et al. 2013). The roads generally involve the addition of sterile and/or reduction in the amount of ore extracted from the optimum pit, which has an impact on the economic value of the mining project (Morales et al. 2017; Nancel-Penard et al. 2019).

Currently, the design of phases in mining is an iterative process of hits and errors that requires a great deal of time. To obtain an operational design and complying with all geometric and geotechnical restrictions depends, in large part, on the experience of the planner, along with the time to make different configurations that allow exploiting the pit according to the planned sequence.

The Delphos mining planning laboratory has developed a methodology that allows ramps design to be assisted in optimizing the undiscounted economic value of the resulting envelope and generating designs that meet geometric and geotechnical constraints through mathematical programming. This paper seeks to apply the methodology proposed by the Delphos mining planning laboratory and compare it with the current design methodology through its application to different open-pit mining operations. 
The document is organized as follows. Section 2 presents the work methodology and design methodologies used in this study, Section 3 describes the case studies and the results obtained. Finally, Section 4 contains the conclusions of this investigation.

\section{Methodology}

The methodology applied in this study is divided into three major stages. The first is to take the block models of each deposit to the optimization stage to obtain the final pit associated with the economic and geotechnical parameters (inter-ramp angle and global angle) of each case.

In the second stage, it seeks to incorporate the ramp from two methodologies. (A) ramp assisted design methodology proposed by the Delphos mining planning laboratory and (B) the current design methodology. For each method, eight design configurations obtained varying the start and turning sense of the ramps are used in the evaluation, and only the one with the best economic benefit is selected to compare them.

Finally, the last stage consists in making a technical and economic comparison of the results obtained by both design methodologies, mainly observing the financial benefit and the number of removable reserves for the final pit of those selected designs.

\subsection{Assisted design of ramps and the current design methodology}

The methodology of assisted ramp design consists of using mathematical programming to find the best possible path that optimizes the economic benefit and meets the geometric and geotechnical constraints of open-pit mining design (Nancel-Penard et al. 2019). This methodology is carried out in the first instance by incorporating certain standard parameters of software input (ramp width, slope, inter-ramp angle and global angle, bench height, turning sense, surface exit point) and the block model of the deposit that has already gone through the open-pit optimization stage. From this, the software delivers a ramp design result with an optimal economic benefit at the block level that must be subsequently softened in a CAD-type software (Computer-aided design) using the ramp previously computed by the economic optimization software.

On the other hand, the current design methodology is based on standard input parameters (slope, ramp width, bench height, bench face angle). With the help of a CAD type software, different ramps configurations are tested, varying either the point of exit to the surface, the orientation of the ramp (clockwise and counterclockwise), and different ways of materializing the ramp (cut, fill, and mixed). This process is repeated until an operational design is reached, which of trials and errors seeks to comply with geotechnical restrictions (inter-ramp and global angle) and obtain an economic benefit that is not so far from that of the financial envelope.

\section{$3 \quad$ Case studies}

The case studies that are used in this work are presented in figure 1. Its main difference is the shape of the deposits and their different geotechnical units (UG) by areas. In this paper, only the first case study is presented in detail, and for the rest of the cases, just an analysis of results is shown. 

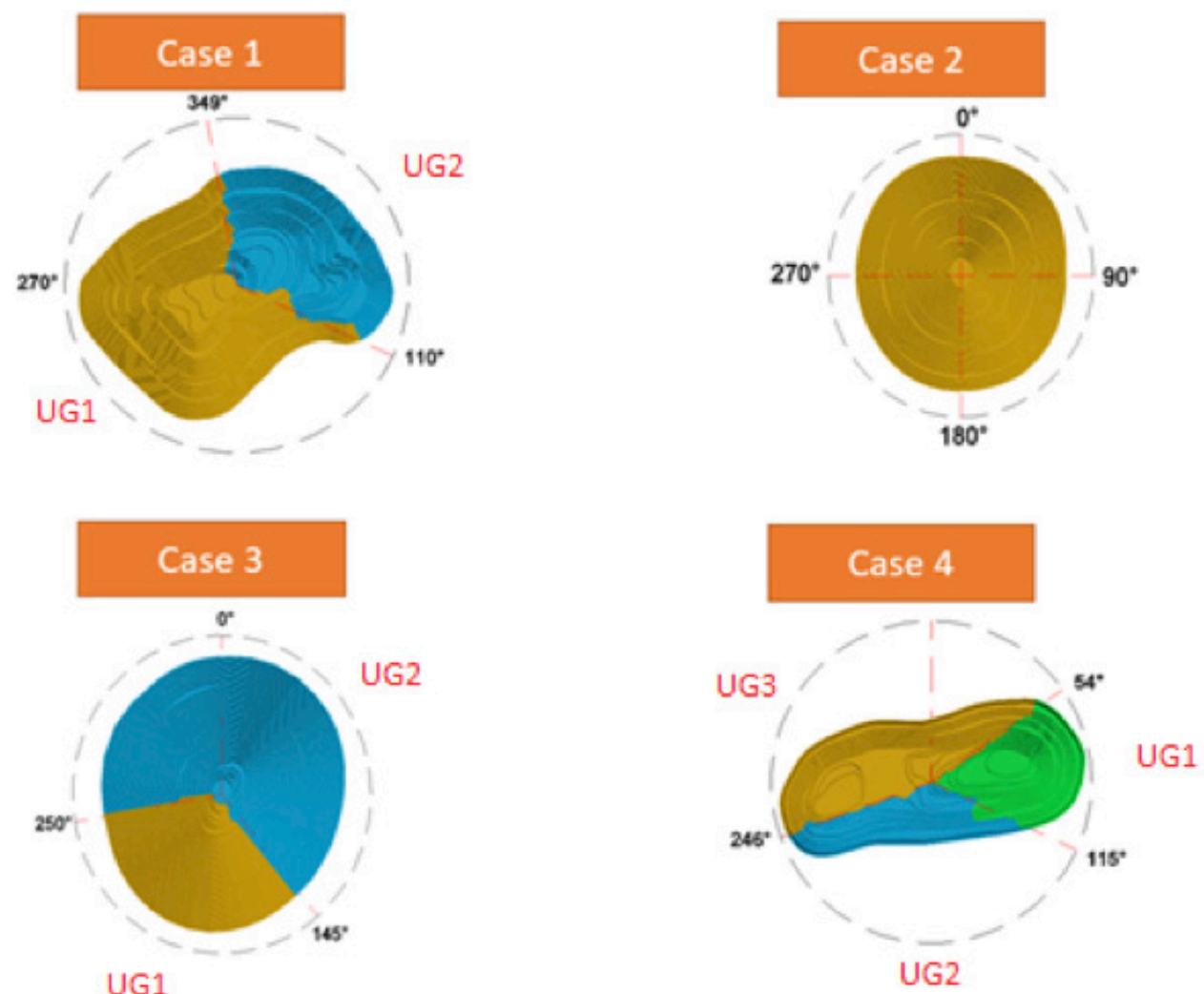

\section{Figure 1 Case studies}

\subsection{Case study No. 1}

Case study No. 1 corresponds to a deposit of copper oxides and sulfides of 340,000 blocks of $20 \times 20 \times 15$. The variables present in the model are the spatial location of each block, using coordinates on the X-axis, Y-axis, and Z-axis, block volume, "rock type" (to make a difference between mineralized blocks of oxides, sulfides and non-mineralized zones). Also, it has a density variable that takes values of $2.54\left(\right.$ ton $\left./ \mathrm{m}^{3}\right)$ and $2.65\left(\right.$ ton $\left./ \mathrm{m}^{3}\right)$ according to the type of rock that corresponds to each block and also the respective Copper grade in percentage.

The economic and metallurgical parameters presented in Table 1 are used to obtain the final pit. These parameters are considered constants over time.

Table 1 Economic scenario for case study No. 1

\begin{tabular}{|c|c|c|}
\hline \multicolumn{3}{|c|}{ Economic scenario } \\
\hline Mine cost & 2.5 & USD/ton \\
\hline Cost plant (Oxide) & 9.8 & USD/ton \\
\hline Cost plant (Sulphide) & 11.4 & USD/ton \\
\hline Cost refining & 661.3 & USD/ton \\
\hline Price metal & 5070.5 & USD/ton \\
\hline $\begin{array}{c}\text { Metallurgical recovery } \\
\text { (Oxide) }\end{array}$ & $85 \%$ & - \\
\hline $\begin{array}{c}\text { Metallurgical recovery } \\
\text { (Sulphide) }\end{array}$ & $92 \%$ & - \\
\hline Discount rate & $10 \%$ & - \\
\hline
\end{tabular}


From figure 1, it's observed that this case study has different geotechnical units (UG). This means that there are different inter-ramp and global angles for each zone. Table 2 shows the details of the geometric and geotechnical data. It is important to notice that the given values of inter-ramp and global angles corresponds to maximum admissible values for the designs.

Table 2 Geometrical and Geotechnical scenario for case study No. 1

\begin{tabular}{|c|c|}
\hline \multicolumn{2}{|c|}{ Geometrical and geotechnical scenario } \\
\hline Bench height & $15 \mathrm{~m}$ \\
\hline Haul road width & $40 \mathrm{~m}$ \\
\hline Ramp slope & $12 \%$ \\
\hline Berm width UG 1 \\
\hline \multicolumn{2}{|c|}{$7.5 \mathrm{~m}$} \\
\hline Bench slope angle & $73^{\circ}$ \\
\hline Inter-ramp angle & $52^{\circ}$ \\
\hline Overall slope angle & $47^{\circ}$ \\
\hline \multicolumn{2}{|c|}{ UG } \\
\hline Bench slope angle & $70^{\circ}$ \\
\hline Inter-ramp angle & $49^{\circ}$ \\
\hline Overall slope angle & $46^{\circ}$ \\
\hline
\end{tabular}

\subsection{Results case study No. 1}

\subsubsection{Final pit}

When applying the traditional optimization methodology, a final pit containing 45,875 blocks is obtained, equivalent to 729 Mton (million tons) of material. The final pit provides $443 \mathrm{Mton}$ destined to the plant with a $0.46 \%$ grade and 285 Mton intended to the dump, with a total economic undiscounted value of MUSD 1,460.

\subsubsection{Current design methodology}

The design configuration with the best undiscounted economic benefit can be seen in Figure 2 and is called "Fill 102 clockwise direction 02". This name indicates that it has a clockwise direction with the point of exit to surface in the West Zone of the deposit. The design contains 469 Mton for the plant with an average grade of $0.45 \%$ and 354 Mton for the dump, which provides an economic benefit of MUSD 1,298 .

With the quantification of this design, we observe the following differences concerning the final pit:

- The total benefit decreases by $11 \%$.

- The materials sent to the plant increases by $5.8 \%$.

- The grade sent to the plant decreases by $2 \%$.

- The material destined to dump increases by $24 \%$. 


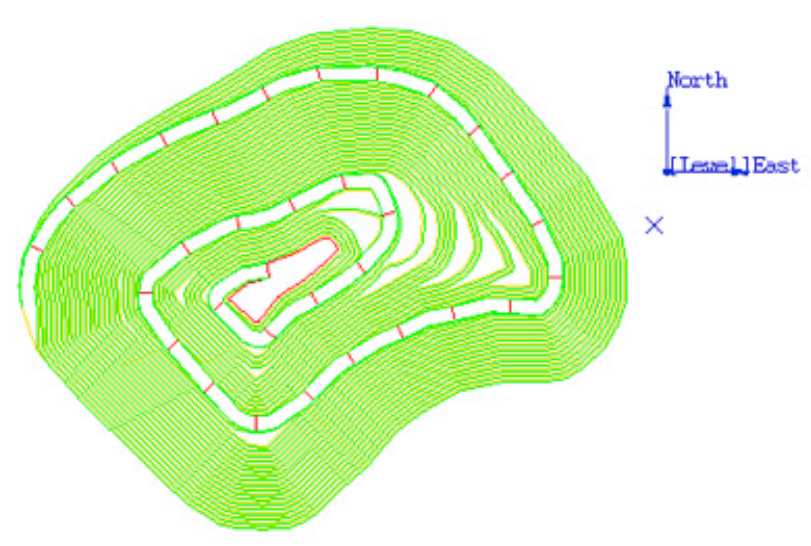

Plan view

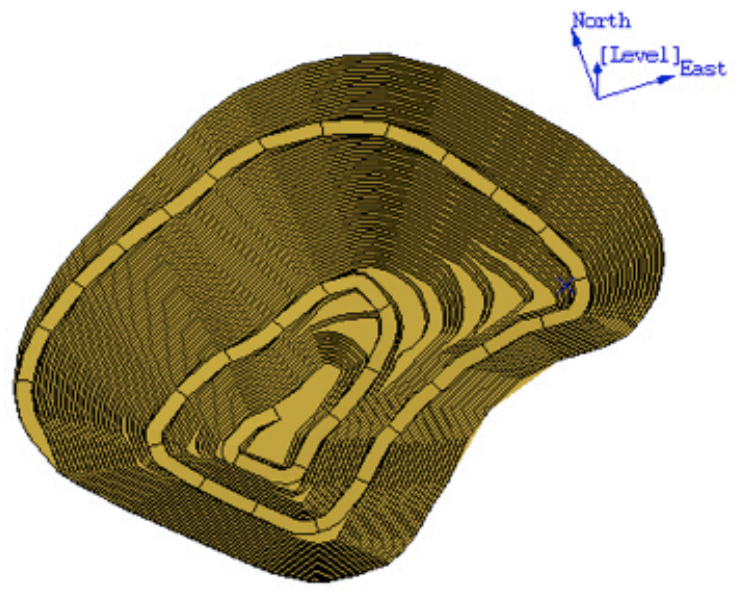

Isometric view

Figure 2 Design "Fill 102 clockwise direction 02"

\subsubsection{Checking angles}

In the background of the case study, there are geotechnical restrictions that must be met (inter-ramp and global angle). To verify that those restrictions are respected in the design, two profiles are made in the pit (Northeast - Southwest, and Northwest - Southeast). The respective cuts and their measurements are shown in Figure 3 and Table 3. Full lines are used to measure the inter-ramp angle, and the dashed line is used to measure the global angle.

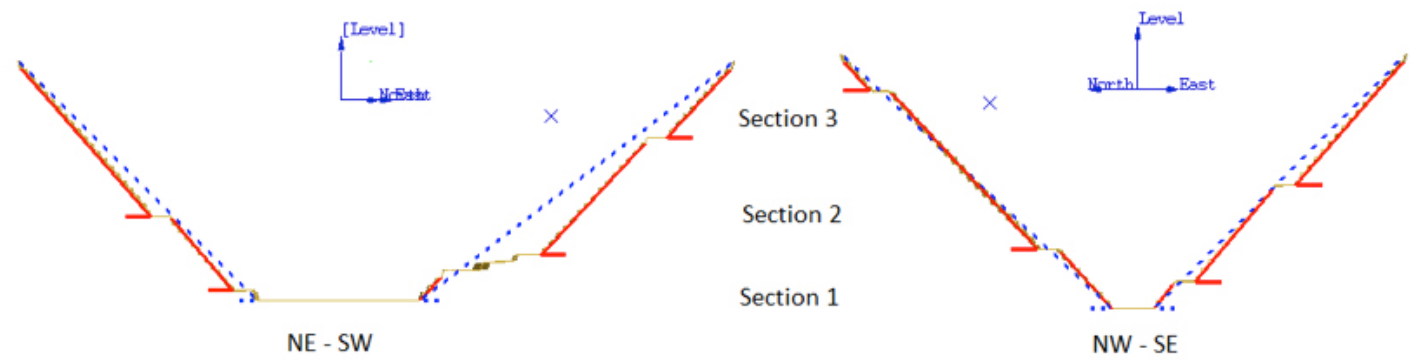

Figure 3 Profiles used to check the inter-ramp and global angle restrictions of the current design methodology

Table 3 Inter-ramp and global angles measured for the "Fill 102 clockwise direction 02" design

\begin{tabular}{|c|c|c|c|c|}
\hline Angle & $\begin{array}{c}\text { Northeast wall } \\
\text { (UG2) }\end{array}$ & $\begin{array}{c}\text { Southwest wall } \\
\text { (UG1) }\end{array}$ & $\begin{array}{c}\text { Northwest wall } \\
\text { (UG1) }\end{array}$ & $\begin{array}{c}\text { Southeast wall } \\
\text { (UG1) }\end{array}$ \\
\hline Overall slope angle & $37^{\circ}$ & $45^{\circ}$ & $43^{\circ}$ & $45^{\circ}$ \\
\hline $\begin{array}{c}\text { Section 1 inter- } \\
\text { ramp angle }\end{array}$ & $47^{\circ}$ & $50^{\circ}$ & $48^{\circ}$ & $52^{\circ}$ \\
\hline $\begin{array}{c}\text { Section 2 inter- } \\
\text { ramp angle }\end{array}$ & $47^{\circ}$ & $49^{\circ}$ & $47^{\circ}$ & $50^{\circ}$ \\
\hline $\begin{array}{c}\text { Section 3 inter- } \\
\text { ramp angle }\end{array}$ & $47^{\circ}$ & - & $48^{\circ}$ & $49^{\circ}$ \\
\hline
\end{tabular}

Table 3 shows that all angles are within the maximum allowed by the geotechnical restrictions in this design.

\subsubsection{Ramp assisted design methodology}

The design configuration with the best undiscounted economic benefit can be seen in Figure 4 and is called "Point 1 clockwise direction". This name indicates that it has a clockwise direction with the point 
of exit to surface in the West Zone of the deposit. The block-level design computed by the mathematical tool contains 444 Mton for the plant with an average grade of $0.46 \%$ and 303 Mton for the dump, which provides an economic benefit of MUSD 1,417.

With the quantification of this design, we observe the following differences concerning the final pit:

- The total benefit decreases by $2.9 \%$.

- The material sent to the plant increases by $0.2 \%$.

- The are no changes in the grade sent to the plant.

- The material destined to dump increases by $6.3 \%$.

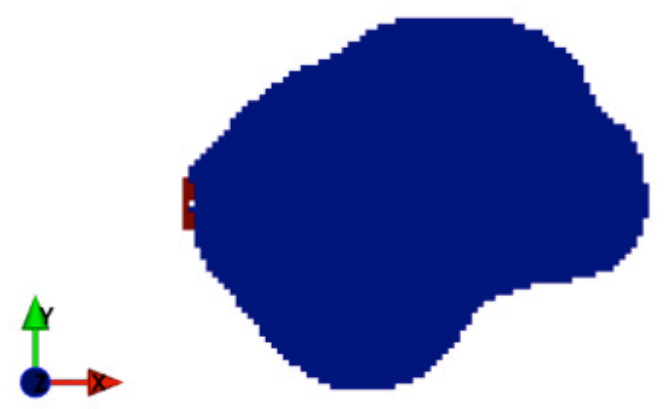

Plan view
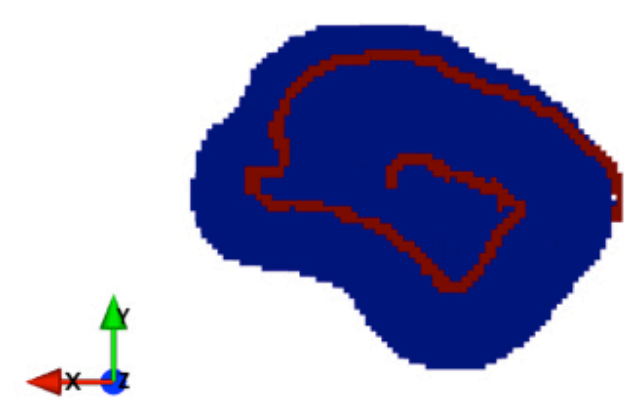

Bottom view

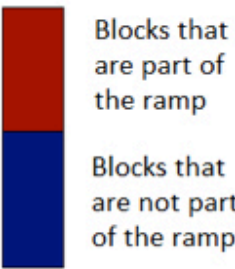

Figure 4 Block-level design computed by the mathematical tool "Point one clockwise"

As discussed in Chapter 3, this block-level design must be smoothed with the help of CAD-type software to make it operational. Figure 5 shows the smoothed design of "Point 1 clockwise direction". This smoothed design that was computed by the mathematical tool contains 439 Mton destined for the plant with an average grade of $0.46 \%$ and 310 Mton destined for the dump, which gives an undiscounted economic benefit of MUSD 1,362.

With the quantification of this design, we observe the following differences concerning the final pit:

- The total benefit decreases by $6.6 \%$.

- The material sent to the plant decreases by $0.9 \%$.

- There are no changes in the grade sent to the plant.

- The material destined to dump increases by $2 \%$.
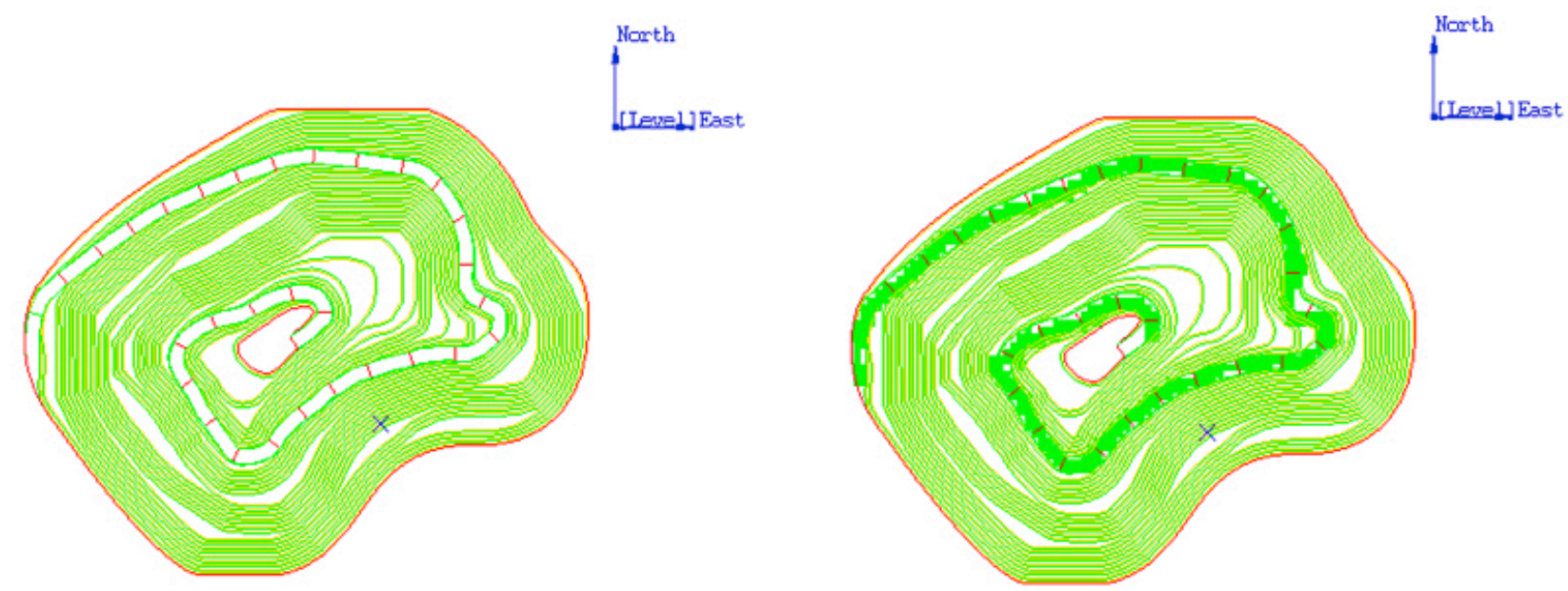

Figure 5 Smoothed design computed by the mathematical tool "Point one clockwise" 


\subsubsection{Checking angles}

An internal validation of the method and verification of angles is performed since the smoothed design incorporates as a new variable the bank face angle and could generate changes in the rest of the parameters. For this validation, it is carried out in the same way as with the current methodology (Northeast - Southwest, and Northwest - Southeast). Figure 6 and Table 4 show the respective cuts and their measurements. Full lines are used to measure the inter-ramp angle, and the dashed line is used to measure the global angle.

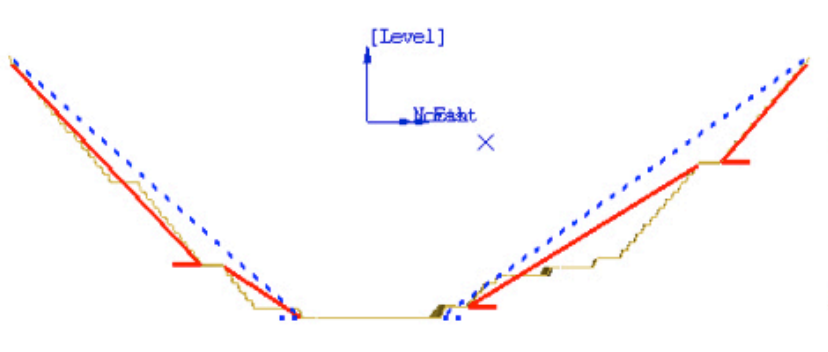

NE - SW

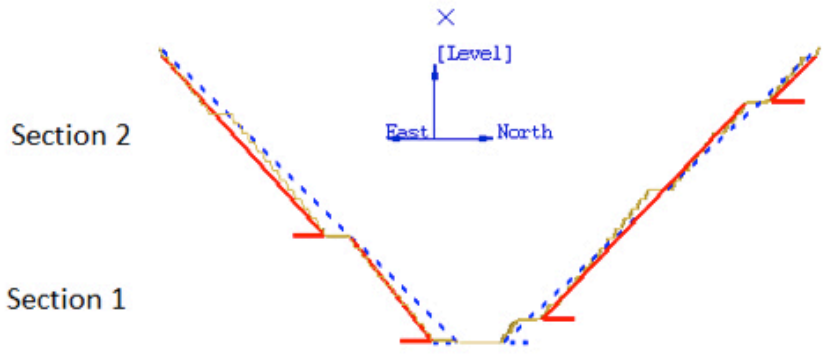

NW - SE

Figure 6 Profiles used to check the inter-ramp and global angle restrictions of the ramp-assisted design methodology

Table 4 Inter-ramp and global angles measured for the smoothed design "Point 1 clockwise"

\begin{tabular}{|c|c|c|c|c|}
\hline Angle & $\begin{array}{c}\text { Northeast } \\
\text { wall [UG2] }\end{array}$ & $\begin{array}{c}\text { Southwest } \\
\text { wall (UG1) }\end{array}$ & $\begin{array}{c}\text { Northwest } \\
\text { wall (UG1) }\end{array}$ & $\begin{array}{c}\text { Southeast wall } \\
\text { (UG1) }\end{array}$ \\
\hline Overall slope angle & $35^{\circ}$ & $42^{\circ}$ & $43^{\circ}$ & $45^{\circ}$ \\
\hline Section 1 inter-ramp angle & $31^{\circ}$ & $33^{\circ}$ & $47^{\circ}$ & $52^{\circ}$ \\
\hline Section 2 inter-ramp angle & $49^{\circ}$ & $47^{\circ}$ & $45^{\circ}$ & $48^{\circ}$ \\
\hline
\end{tabular}

Table 4 shows that all angles are within the maximum allowed by the geotechnical restrictions in this design.

\subsection{Analysis of results case study No. 1}

Using the methodology of assisted ramp design over the current design methodology, the following is achieved:

- The total undiscounted benefit increases by $4.3 \%$, a percentage that is equivalent to MUSD 64 .

- The grade of the material sent to the plant increases by $2.2 \%$.

- The material sent to plant decreases by $6.3 \%$.

\subsection{Analysis of results of case studies No. 2, 3 and 4}

For the rest of the case studies, the results have the same tendency as in case study number 1 . Table 5 summarizes the results of case studies No. 2, 3, and 4 when using the ramp assisted design methodology. above the current design methodology. ( $>$ no variation, $\boldsymbol{\nabla}$ result decreases, $\boldsymbol{\Delta}$ result increases). 
Table 5

Results for case studies No. 2, 3 and 4

\begin{tabular}{|c|c|c|c|}
\hline & Case study 2 & Case study 3 & Case study 4 \\
\hline $\begin{array}{c}\text { Grade of the material } \\
\text { sent to the plant }\end{array}$ & $0 \%$ & $\Delta 6.3 \%$ & $\Delta 1.1 \%$ \\
\hline Material sent to the plant & $\boldsymbol{\nabla} 0.77 \%(0.5$ Mton) & $\boldsymbol{\nabla} 18.4 \%$ (73 Mton) & $\Delta 0.8 \%$ (0.7 Mton) \\
\hline Total benefit & $\mathbf{\Delta 2 . 2 \% ( 2 8 . 2 \text { MUSD) }}$ & $\begin{array}{c}\Delta 1.08 \%(35.6 \\
\text { MUSD) }\end{array}$ & $\Delta 2.5 \%(41.5$ MUSD) \\
\hline
\end{tabular}

\section{$4 \quad$ Conclusions}

An analysis of the application of the assisted design of ramps in four mining operation is carried out and compared with the use of the current design methodology. This way, the differences between the operational models of both methodologies and the final pit for every case study are sought through economic benefit and the material sent to the plant.

With the method of assisted ramp design, a slight improvement in the economic benefit and a slight decrease in the material sent to the plant is achieved. This improvement is in a range from $1 \%$ to $4.5 \%$ for the undiscounted economic benefit and a range from $-18.4 \%$ to $+0.8 \%$ for the material sent to the plant, depending on the case. Also, with the use of the methodology of assisted ramp design, it is evidenced that it is a tool that allows the generation of multiple designs and iterations in short periods complying with geometric and geotechnical restrictions through mathematical programming.

Ramp assisted design is a methodology that works and manages to generate designs that meet the fundamental constraints of the problem, and that allows the planner to make decisions in the design. All this is achieved in a shorter period of time as a result of the simplicity of introducing the necessary parameters in the software, and that through mathematical programming generates different predesigned results.

\section{Acknowledgment}

Part of this work was funded by the CONICYT/PIA Project AFB180004

\section{References}

Hustrulid, W, Kuchta, M, \& Martin, R 2013, 'Open Pit Mine Planning \& Design', Taylor \& Francis Group.

Morales, N, Nancel-Penard, P, \& Parra, A 2017, 'An Integer Linear Programming Model for Optimizing Open Pit Ramp Design', In 38th APCOM proceedings, Chapter 11, pp. 9-16.

Nancel-Penard, P, Parra, A, Morales, N, Díaz, C, \& Widzyk-Capehart, E 2019, 'Value-optimal design of ramps in open pit mining', Archives of Mining Sciences, vol. 64, no. 2, pp. 399-413. 